\title{
NASA ARC
}

\section{GALILEO PROBE BATTERY SYSTEM}

\author{
B. P Dagarin, R. K. Taenaka, and E. J. Stofel \\ Hughes Space and Communicatione Company, El Segundo, CA 90245 \\ Presented at the \\ 1996 NASA Aerospace Battery Workshop
}

December 3-5, 1996

At the Huntsville Hilton Hotel

Huntsville, Alabama

- Battery performance met mission requirements, with margin

- Extensive ground-based and flight tests of batteries prior to Probe separation from Orbiter provided good prediction of actual entry performance at Jupiter

- Li-SO $\mathrm{S}_{2}$ battery was an important choice for Probe's main power:

- good energy density,

- established manufacturing processes,

- excellent energy retention in extended storage,

- acceptable limit on voltage delay at start-up

\section{ACKNOWLEDGMENTS}

- The Galileo Probe was designed and bullt by Hughes Space and Communlcations under the direction of the NASA Ames Research Center, Contract NAS 2-10000

- LL-SO $\mathrm{O}_{2}$ batterles were manufactured by Alliant Techsystem Power Sources Center (prevlously Honeywell PSC), with conttnuing technical support during entire mission

- Thermal batterles were manufactured by Eagle-Picher Industries

- Dual use of $\mathrm{LJ}-\mathrm{SO}_{2}$ and thermal batterles was suggested by General Electric

- Supportive diagnostic measurements and helpful discussions were provided by several personnel at the Sandia Natlonal Laboratories 

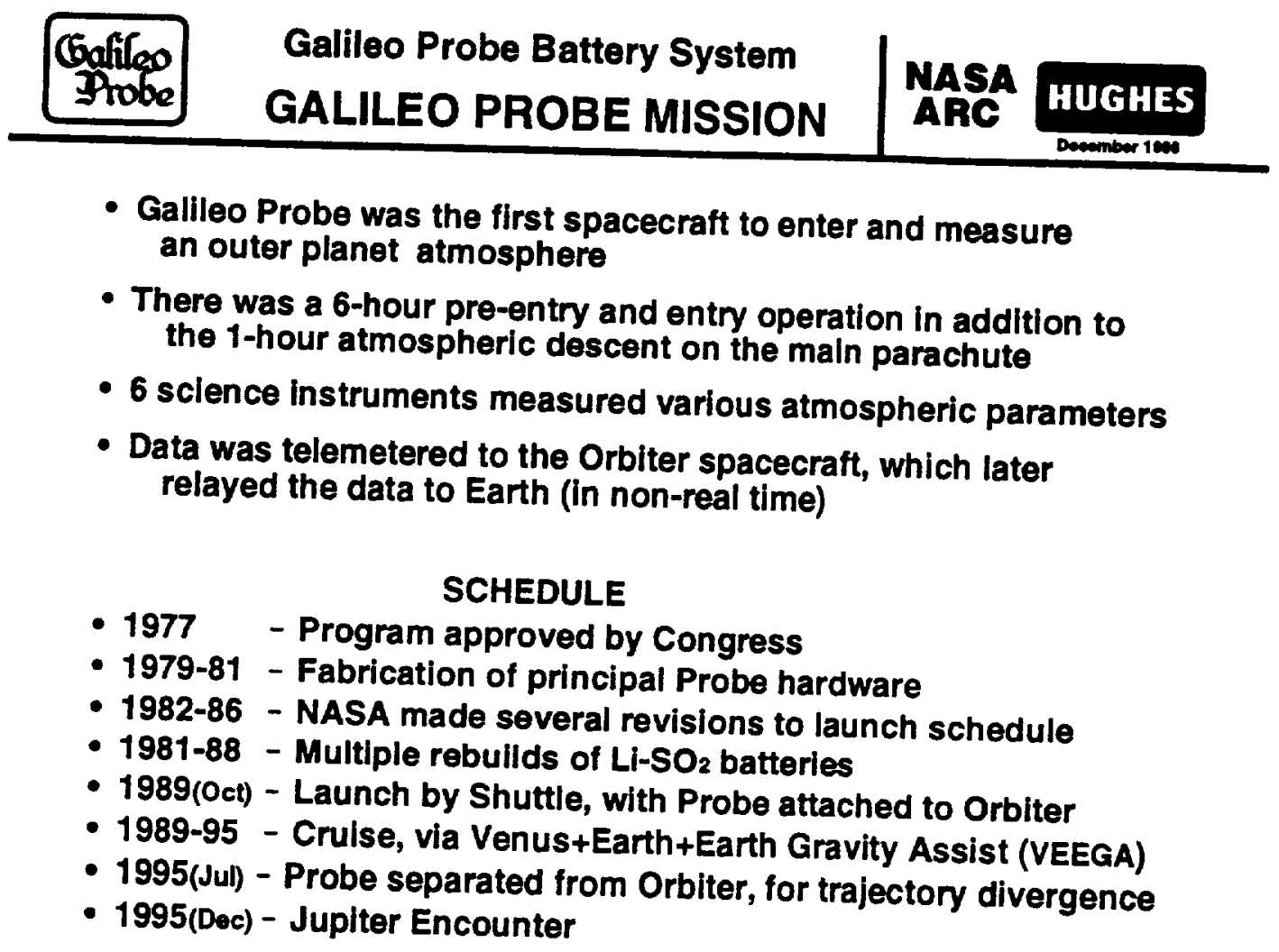

The Galileo Probe required an internal source of electrical power. The source was required to remain quiescent for several years with minimum loss of stored energy, then be activated to drive the scientific instruments and the radio transmitter for a few hours as the Probe approached and then entered the Jovian atmosphere. Primary batteries were ideal for this application.

The $\mathrm{Li} / \mathrm{SO}_{2}$ batteries were built by Honeywell Power Sources Center, in Horsham, Pennsylvania (recently renamed Alliant Techsystems). Because the Galileo Program was very ambitious, several times during its development the launch schedule was postponed. Most of these were due to difficulties in providing an adequate launch vehicle for the mission. None of these delays were ever due to any problems with the batteries-nevertheless, with each Program delay new $\mathrm{Li} / \mathrm{SO}_{2}$ batteries were fabricated so that the freshest possible units would be available for the revised launch schedule. Thus, battery manufacturing and testing was repeated several times at Alliant. The first acceptable flight units were from manufacturing Lot 3 , the final units, as used for the actual Galileo flight, were from Lot 10 . While most of the intervening lots demonstrated adequate performance during their respective lot qualification tests, it is interesting to note that Lots 3 and 10 showed the best performance. The commonalty between these two great lots was the fact that their electrolyte was mixed by hand rather than by a mechanized batch mixer that was common to the intervening lots.

The thermal batteries were built by Eagle Picher Industries in Joplin, Missouri. Development of these had included a redesign of the header insulation. The batteries of manufacturing Lot 6 passed all qualification tests well. Because of the Galileo Program delays, there were recertification tests run on samples of these thermal batteries, but these tests showed that there was no need to rebuild fresher batteries. 


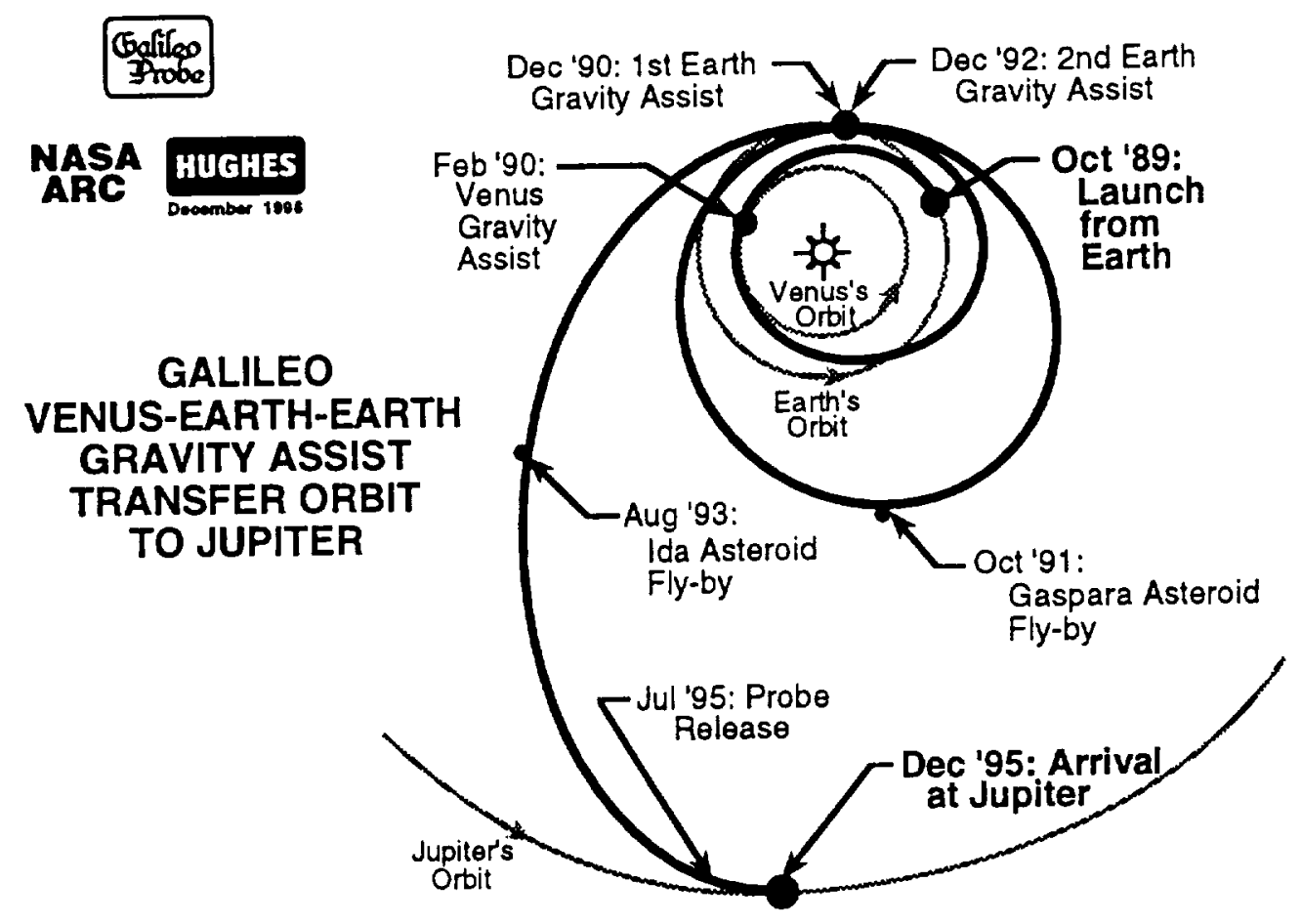

The VEEGA mission was devised by JPL in 1986 as an alternate to the originally planned direct route to Jupiter. That direct route had to be abandoned after the required Centaur upper stage was declared unsuitable for use with any future Shutcle launch-it was deemed to be potentially too dangerous by the committee that conducted the in-depth NASA safety review that had followed the disastrous launch attempt of the Challenger Shuttle in January 1986. Upon the acceptance of the VEEGA alternative, the transit time from Earth to Jupiter escalated from the 2 years that had been planned for the Centaur driven direct transit to a 6 year VEEGA journey following a circuitous route of approximately 2.4 billion miles.

The tripling of the transit duration was a real concern to the battery engineers-there were insufficient data available at that time to assure that $\mathrm{Li} / \mathrm{SO}_{2}$ batteries would remain fully viable for such a long duration. We initiated a life-time assessment study at Sandia National Laboratories (SNL) under the direction of Dr. Sam Levy, using representative sample cells subjected to a variety of elevated temperatures. That comprehensive and enlightening study is documented in SNL Report No. SAND88-2218-UC-94C. The shelf life changes found by the SNL work indicated a worse case loss of no more than $0.04 \mathrm{Ah} / \mathrm{yr}$, assuming a 6 year temperature of $0^{\circ} \mathrm{C}$, the temperature expected for the VEEGA transit. This was considerably more optimistic than the $0.2 \mathrm{Ah} / \mathrm{yr}$ assumption that had been used until that time. This represented a substantial reduction in the estimate of the battery capacity loss, giving the battery engineers and the Probe Program Office a great deal of confidence in the stability of our primary power system. 


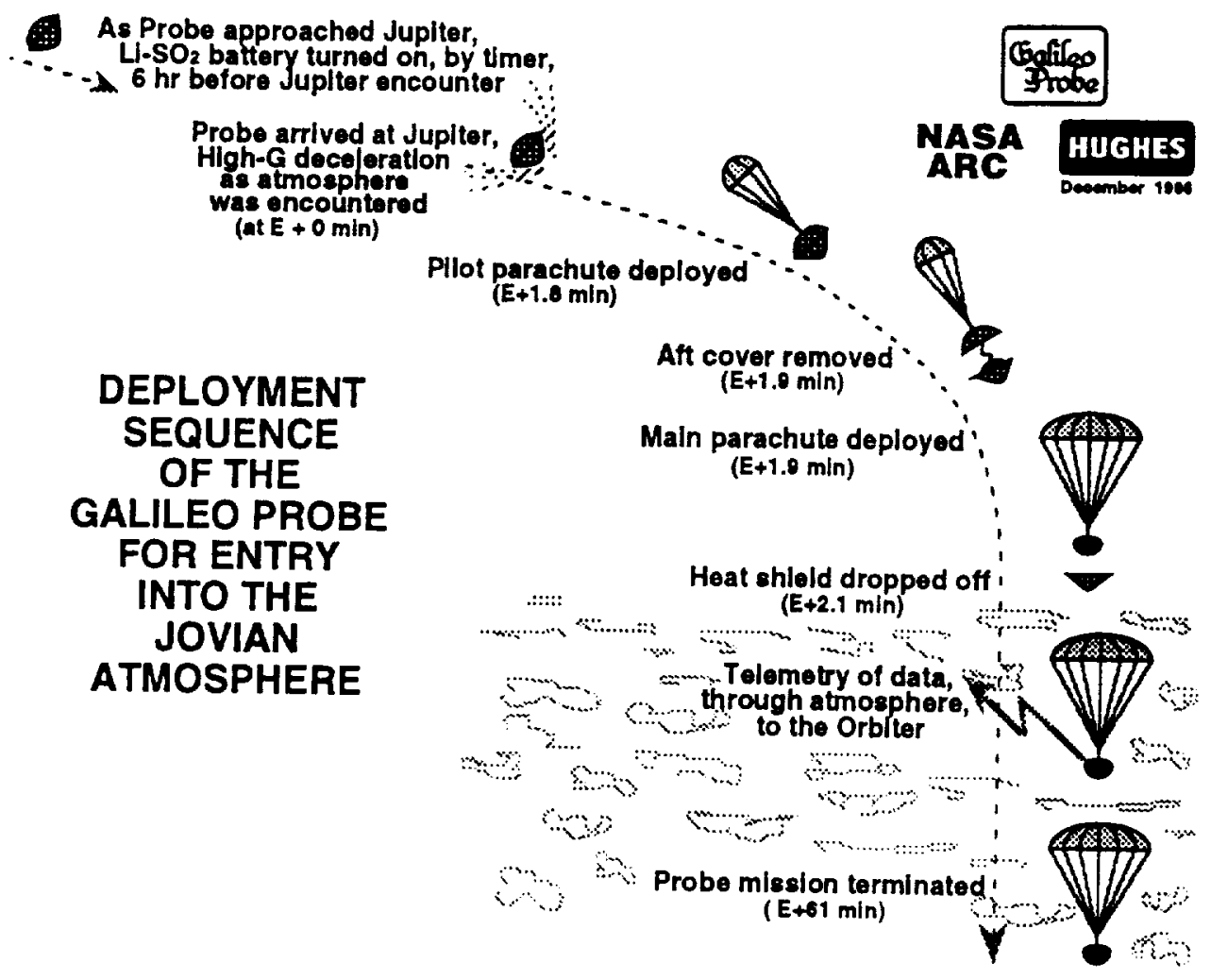

The Probe was separated from the Orbiter near midnight on July 12,1995. The Probe was released on a ballistic trajectory toward its target zone on Jupiter at $6.57 \mathrm{deg} \pm 0.5 \mathrm{deg}$ north latitude near the night-day terminator with an entry flight path angle of $-8.6 \mathrm{deg} \pm 1.4 \mathrm{deg}$. We were well within the tolerance on both parameters.

Before Probe release, the modest power requirements of the Probe had been supplied by the attached Orbiter through an umbilical cord. After release, all Probe power was supplied by its on-board batteries. For the subsequent 5 month Coast phase the only significant electrical load was the on-board clock, set to awaken the Probe's electronics 6 hours prior to Encounter. The clock was set just before Probe release. It ran from only battery Module 3, leaving the other two modules undisturbed. The 5 month wake-up occurred with precision-within 18 seconds of the nominal time even though a tolerance of 8.6 minutes would have been permitted.

The Probe functioned flawlessly throughout the Coast and the Pre-Entry Periods. All of the Coast and the first 5.5 hours of the Pre-Entry period were single string operations. Initial turn-on, at Entry-6 hr, was the time at which the three battery modules underwent their battery clean-up (or depassivation) of the lithium anodes.

At the atmospheric Encounter, the Probe survived entry deceleration and its heating very nicely but was 53 seconds late in deploying the main parachute. This was due to a harness wiring error-the thermal and $\mathrm{Li} / \mathrm{SO}_{2}$ batteries satisfied all their Entry deployment functions properly.

The parachute controlled Descent phase operated well, with the $\mathrm{Li} / \mathrm{SO}_{2}$ batteries providing all required power. The Probe achieved a depth equivalent to 24 bars pressure before we lost our RF link due to extreme temperanure and pressure on the RF transmitter. This Probe performance exceeded our core mission requirement, which had been merely to reach at least 10 bars. 


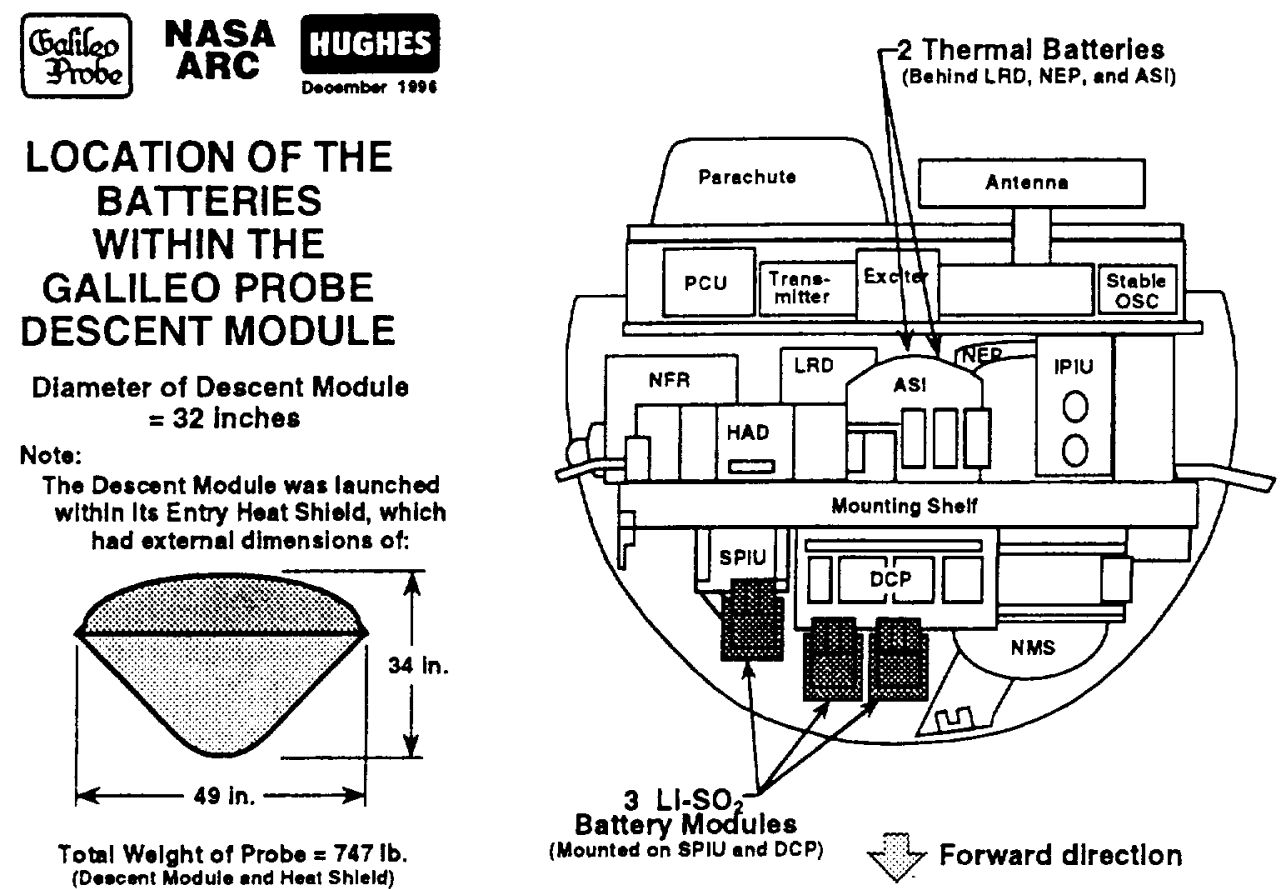

The descent module was designed and built by Hughes Space and Communication Company. A major subcontractor was the General Electric Re-Entry Systems Division (now part of Lockheed-Martin) who designed and built the deceleration subsystems, i.e., the heatshields, separation mechanisms, and the parachutes.

The descent module was designed to be as compact as possible to minimize the size and therefore the weight of the surrounding heat shield. The electronics and all other components therein were very densely packaged. The mechanical design of the battery modules provided a conformal shape to match the limited space. It also provided mechanical ruggedness to survive Entry deceleration along with thermal isolation during discharge to protect sensitive surrounding electronics.

The Probe's science instrument compliment and principle investigators are:

Neutral Mass Spectrometer: Hasso Niemann, NASA-GSFC

Hclium Abundance Detector: Ulf von Zahn, Univ. of Rostock, Kühlungsborn, Germany

Atmospheric Structures Instrument: AJvin Seiff, San Jose State Univ. Foundation, San Jose, CA

Nephelometer: Boris Ragent, San Jose State Univ. Foundation, San Jose, CA

Net Flux Radiometer: Larry Sromovsky, Univ. of Wisconsin, Madison, WI

Lightening \& Radio Emissions Detector: Louis Lanzerotti, Lucent Labs., Murray Hill. NJ

Energetic Particle Instrument: Harold Fischer, Univ. of Kiel. Kiel, Germany

Doppler Wind Experiment: David Atkinson, Univ. of Idaho, Moscow. ID

The science instrument package weighed $66 \mathrm{lb}, 24 \%$ of the $278 \mathrm{lh}$ descent module.

The three $\mathrm{Li} / \mathrm{SO}_{2}$ modules weighed a total of $16.5 \mathrm{lb}, 6 \%$ of the total descent modulc. Each of these battery modules was $2.8 \mathrm{in.}$ by $3.5 \mathrm{in}$. by $14.0 \mathrm{in}$. 

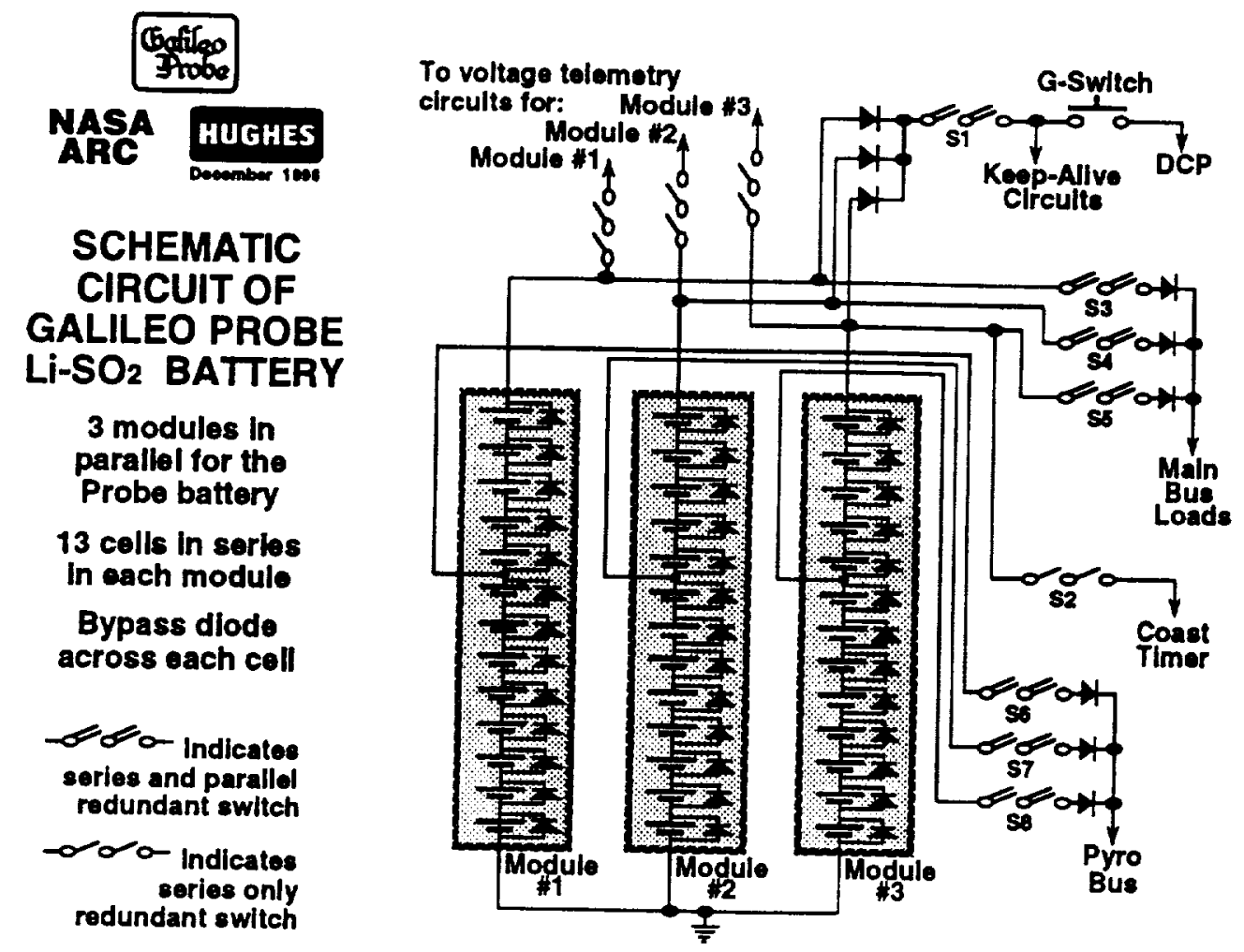

The Probe power subsystem was a simple but well planned design with careful effort put forth to assure that the $\mathrm{Li} / \mathrm{SO}_{2}$ battery modules were provided the utmost protection from detrimental effects of any inadvertent single part failure. Special attention was given to circuit failures that might prevent any module from being coupled to the mission loads under command or that might inadvertently drain any battery module prior to the Probe's arrival at Jupiter. The above schematic battery circuit shows locations of key redundant series+parallel switches.

The modules were also designed with internal by-pass diodes across each cell so as to prevent the loss of a complete module if any one of its constituent cells would have failed due to an open circuit, an abnormal capacity loss, or by any other means.

Each module was equipped with two sets of electrical connectors: a power connector and a test/by-pass connector. The latter permitted fusing, as a safety precaution, during all ground-based system tests. Furthermore, whenever the by-pass fused plugs were physically removed, the modules became disarmed so that it was impossible to discharge any of them even if a power switch had been closed inadvertently during any test operation. As final preparation before launch, at the launch site, the fused by-pass plugs were removed; and hard wired plugs substituted. After that time, the three module power connectors provided direct access, without fusing, to the above indicated switches leading to the Probe's power bus.

Just prior to launch, as well as multiple times during the preceding ground tests, we measured the wire harness between the modules and the power relays under applied system voltage to verify that any current leakage was less than $150 \mathrm{nA}$. This low leakage requirement was especially important for assuring that any external battery drain during the 6 year transit from Earth to Jupiter would be negligible. 


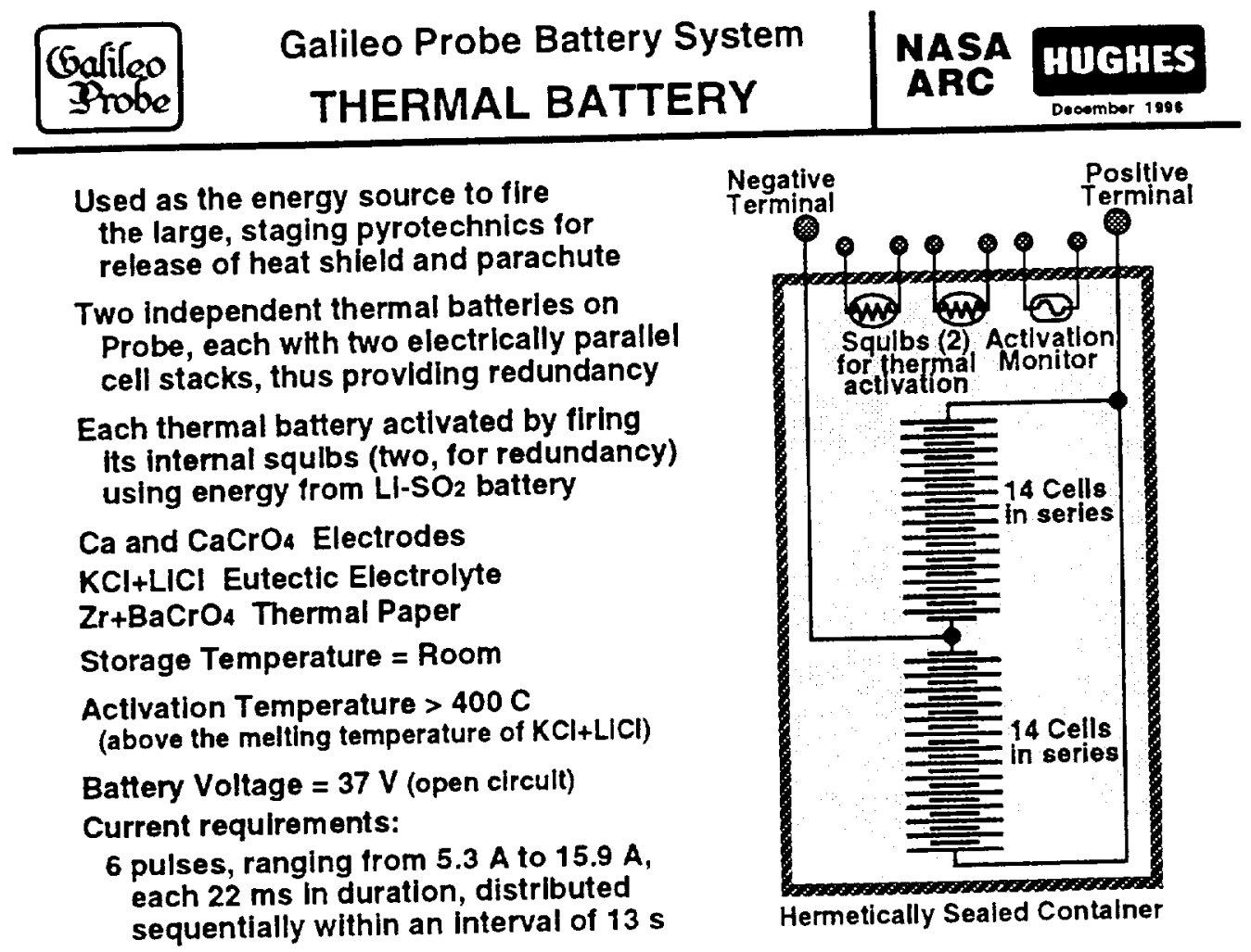

The $\mathrm{Ca} / \mathrm{CaCrO}$ thermal batteries were used for the sole purpose of supplying the few large current pulses required for firing the pyrotechnic pressure cartridges that jettisoned the heat shields and deployed the parachute. The use of these supplemental, single purpose batteries avoided placing large pulses on the main power bus which could otherwise have had a deleterious impact on the Probe's command sequencer.

The two miniature squibs within each thermal hattery were redundant, fired sequentially from an 8-cell tap on each of the three 13-cell $\mathrm{Li} / \mathrm{SO}_{2}$ modules. The later three modules operated in parallel, for redundancy. The demand for the pulsed power to activate the large cartridges occurred within an interval of less than a minute, so thermal batteries were the logical choice for this application. They remained hot. and therefore active, for longer than was necessary to satisfy the pulsed current requirements.

Systems development tests demonstrated that a small, resistive load connected continuously across the activated thermal batteries aided the maintenance of their voltage stability during the pulsed load demands The thermal batteries had more than enough capacity to supply that small continuous load as well as the large pulses.

The performance of the thermal batteries during the actual descent of the Probe into the Jovian atmosphere was not monitored directly-their rise in voltage and their all important current pulses would have been too rapid to have been recorded at the low data rate that had been allocated for monitoring functions within the Probe. However, from our analysis of the overall flight data we can deduce that the thermal batteries performed their required function, releasing the heat shield and parachute upon demand. 

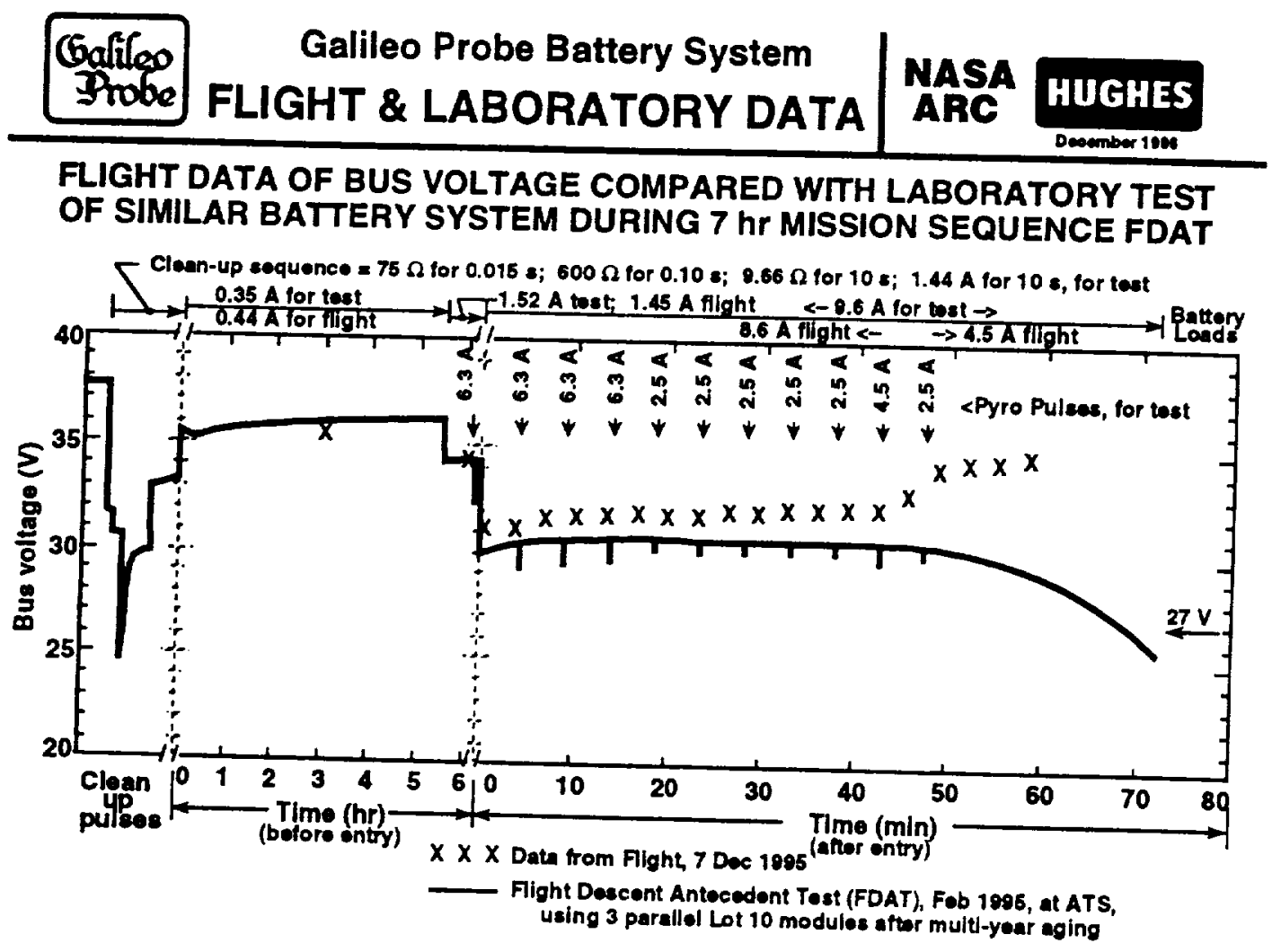

To say that we were pleased with the performance of our $\mathrm{Li} / \mathrm{SO}_{2}$ battery modules on December 7 , 1995, would be an understatement. They performed precisely as predicted.

The solid line in the above graph represents the performance of three similar battery modules in a real-time laboratory simulation of the 6-hour Pre-entry and the hour of Descent. This was the concluding portion of the Flight Descent Antecedent Test (FDAT), a test executed to simulate total flight performance in real time as closely as practical and thereby provide a useful tool for predicting flight performance. The test modules were from the same manufacturing lot as the flight modules. Their temperature was controlled meticulously the entire time after manufacture to mimic the temperature history of the flight modules during the Launch, Cruise, Coast, Pre-entry, and Descent phases of the Probe's mission. The Coast phase simulation lasted 155 days, including a simulated clock load. The FDAT was completed on February 21 , 1995-in sufficient time before the Probe's release from the Orbiter (July '95) to permit analysis of the FDAT data and to consider their systems operational implications.

Our two voltage data points from the Pre-entry flight time matched the FDAT predictions very well. The first flight point is a little low, as expected because the flight load was slightly larger than the FDAT load at the equivalent time. On the other hand, the Descent voltage profile from flight was slightly higher than that from the FDAT, due to both lighter loads in flight and a higher temperature beginning at Entry +30 minutes. The jump in flight voltage at $\approx$ Entry +47 minutes was due to the loss of RF String B and the resultant decrease in bus loads of 4.1 $\mathrm{A}$.

We believe that the flight $\mathrm{Li} / \mathrm{SO}_{2}$ battery had sufficient remaining energy to have lasted, even if full load had been maintained, to reach our predicted battery operation duration of Entry+76 minutes. 

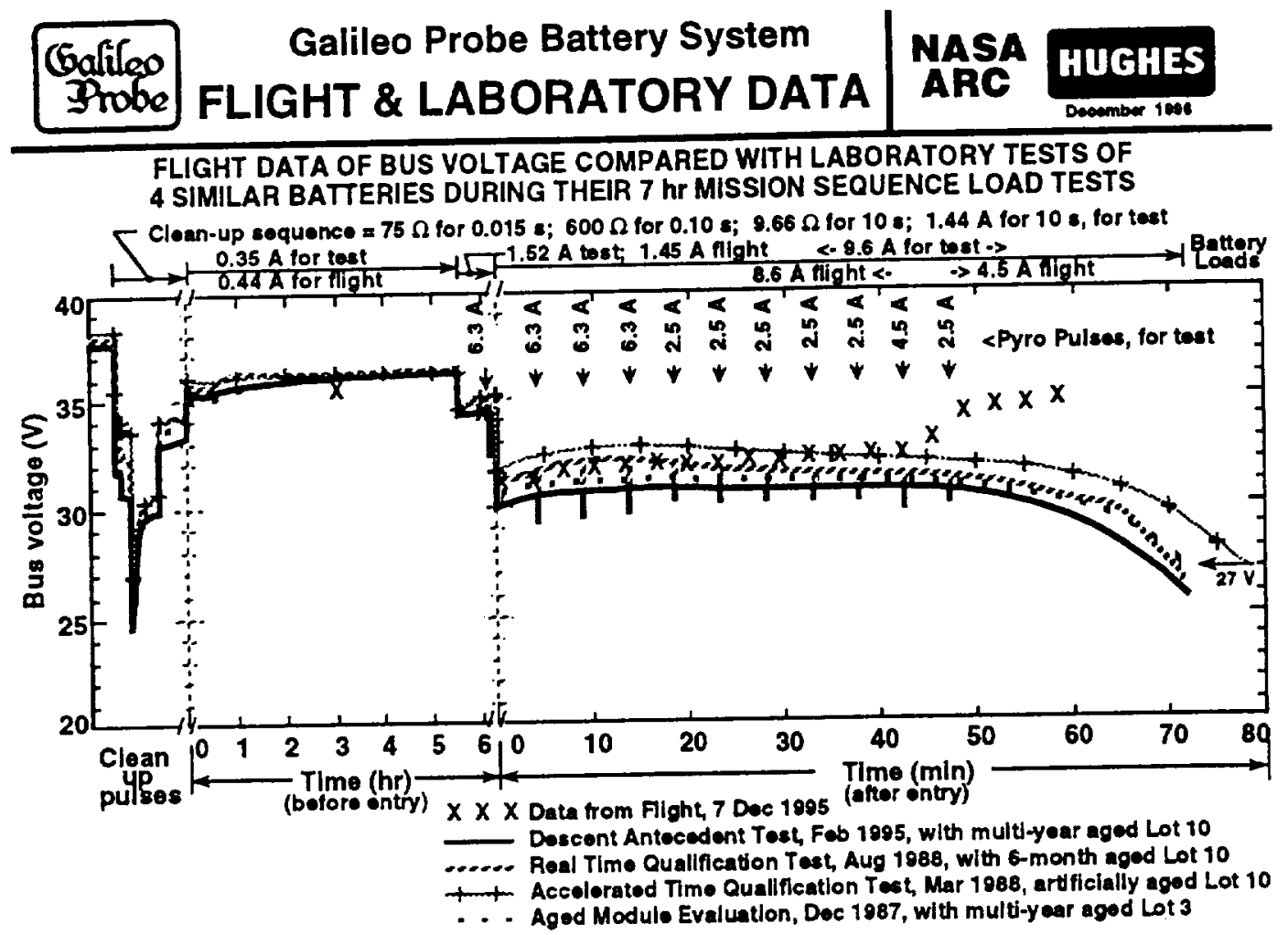

This interesting graph compares the flight data with the results of several preceding laboratory battery tests. The solid line is for the FDAT, our best ground simulation of flight conditions, as explained with the preceding graph. The line with the slanted stripe pattern is the Real Time Lot 10 Qualification Test, completed 6 months following manufacturing. It had a real time simulation of the 5 month Coast interval. However, the preceding simulation of the 5.5 year Cruise phase was highly accelerated-a $1.1 \mathrm{Ah}$ discharge (over $4.5 \mathrm{hr}$ ) of each of the three module to approximate the capacity loss estimated for 5.5 years of quiescent storage. The line with periodic crosses depicts the result of the even faster Accelerated Lot 10 Qualification Test wherein a $60 \mathrm{hr}, 6.0 \mathrm{Ah}$ discharge of only Module 3 was used to simulate capacity loss for all modules for both the Cruise and the Coast phases. The dotted line is the result of testing Lot 3 modules which had been quiescently stored for several years as an approximation for the Cruise phase (but without the precise temperature control used for the Lot 10 FDAT). Following this Cruise approximation, the Lot 3 modules had a real time, 5 month Coast simulation with the standard clock load. No accelerated loads had been applied to those Lot 3 modules prior to the discharge depicted in the above graph.

One can clearly see the difference in voltage response (to the $9.6 \mathrm{~A}$ ground test simulation of the Descent load) between the Real Time and the Accelerated Lot 10 Qualification Tests. This difference was common to every lot for which their testing had included both versions of time simulations. This provides a clear justification for real-time system level testing for this electrochemical system. This 7 to 8 minute difference in time to reach the $27 \mathrm{~V}$ lower limit for satisfactory systems operation is significant for its imporance to the mission performance prediction, as it represents $10 \%$ of the critical Descent portion of the mission. 

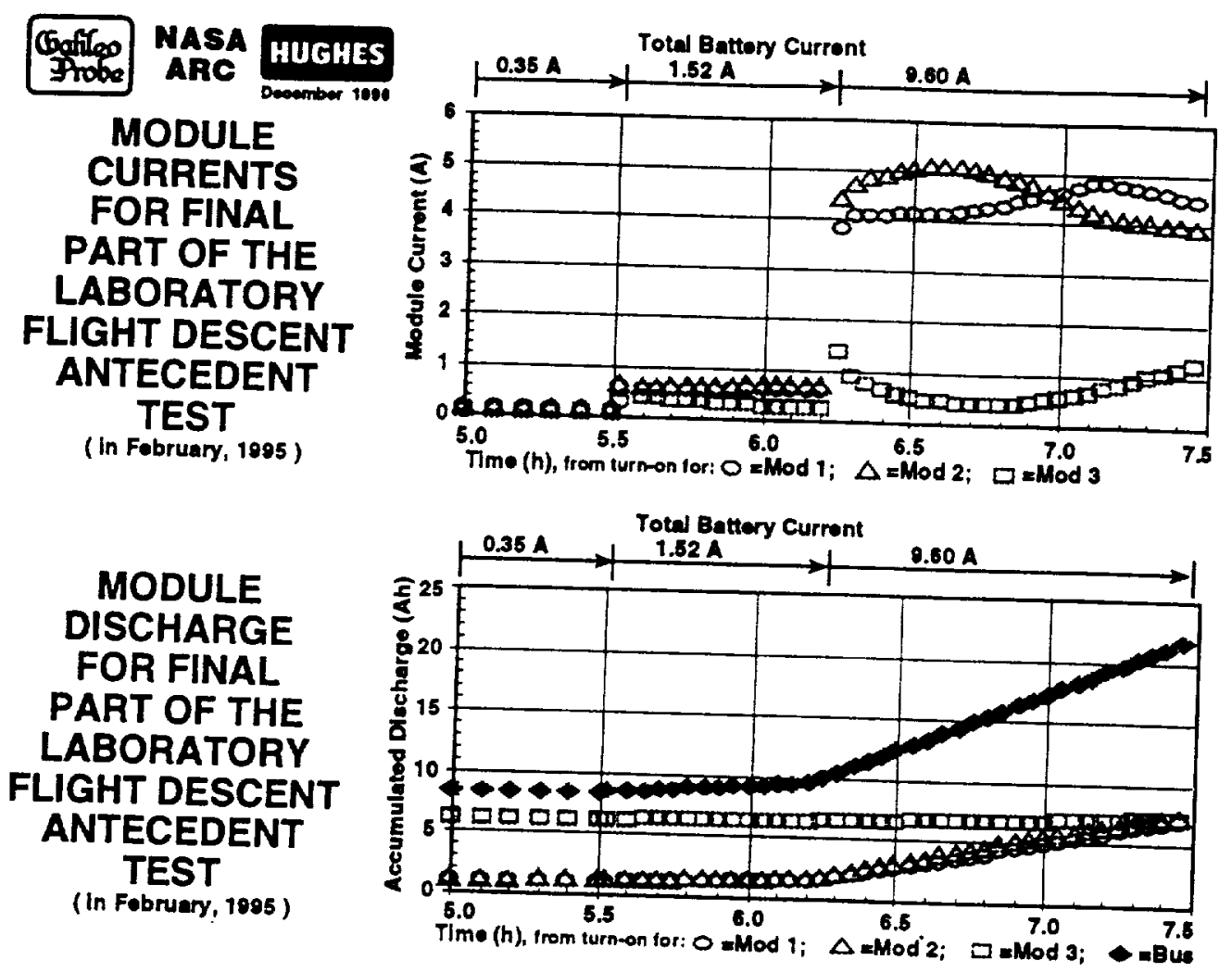

These two graphs illustrate the efficiency of our Probe battery system in terms of sharing current as well as delivering Ah capacity. The top graph depicts how Module 1 and Module 2 supplied most of the current during the 9.6 A Descent phase of the FDAT simulated mission. Module 3 had already expended more than half of its capacity supporting the clock during the real-time 155-day Coast phase, yet during the Descent phase even that module was still able to contribute all of its remaining energy to the common bus. The Descent phase of this FDAT concluded when each of three modules simultaneously reached the same limit in their capacity, as can be seen by comparing the delivered Ah results in the lower graph. This was the expected result, arising from the parallel design of the three-module battery.

The cross-over (i.e., the wave pattern in the top graph) of the currents that were supplied individually by Module 1 and Module 2 during Descent was a pattern noted throughout the several discharge tests at Honeywell (Alliant) and was also seen the during systems test on the Probe. We believe this also occurred in flight (but individual module currents were not monitored in flight)-it answers the question of why the temperatures (which were monitored in flight) of the two modules differed in their rate of change. Module 2's flight temperature initially rose at the faster rate but then slowed down. Module 1 at first rose slowly but ended with a more rapid rate. By the end of the 60 minutes of available flight Descent data, both modules had arrived at similar temperatures, indicating by that time they had supplied equal amounts of integrated Ah during their respective discharges, another aspect of the expected response for modules connected in parallel. 


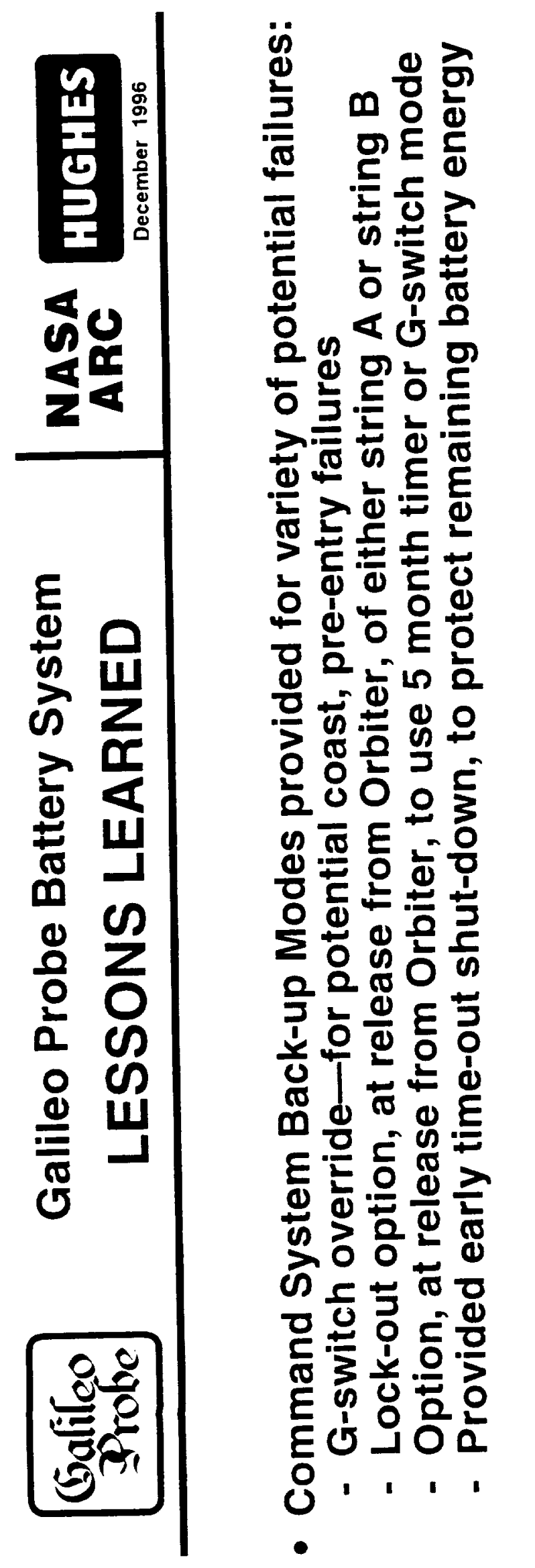

1996 NASA Aerospace Battery Workshop

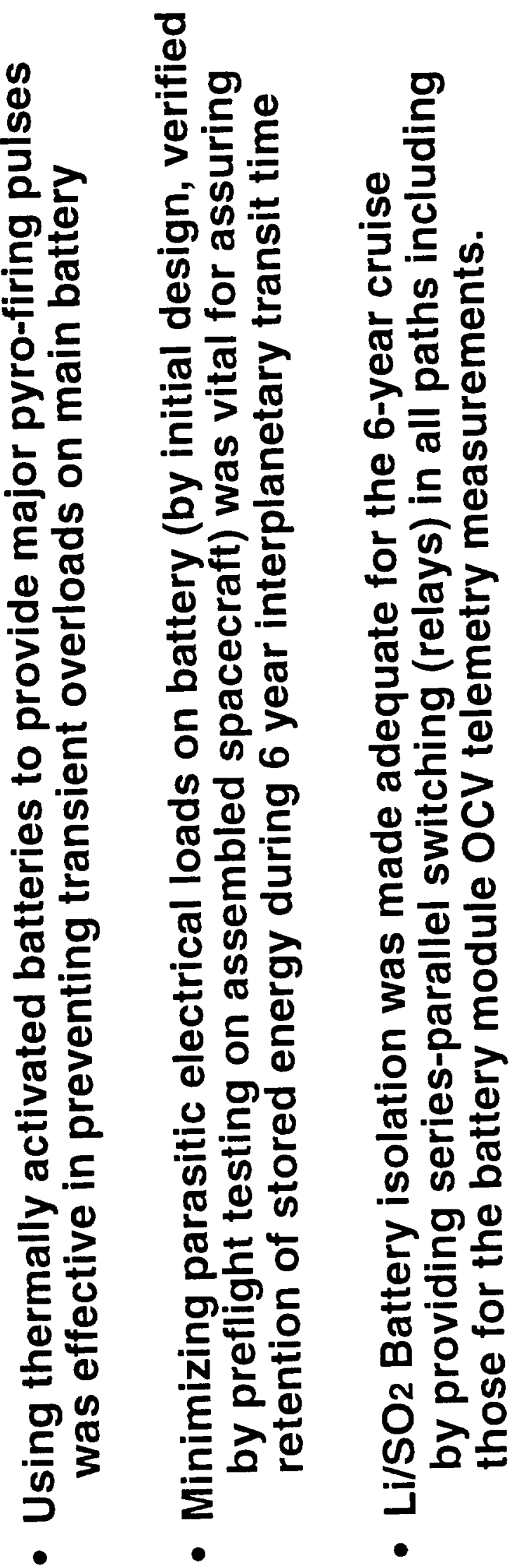

$-143-$
General / Primary Battery Session 


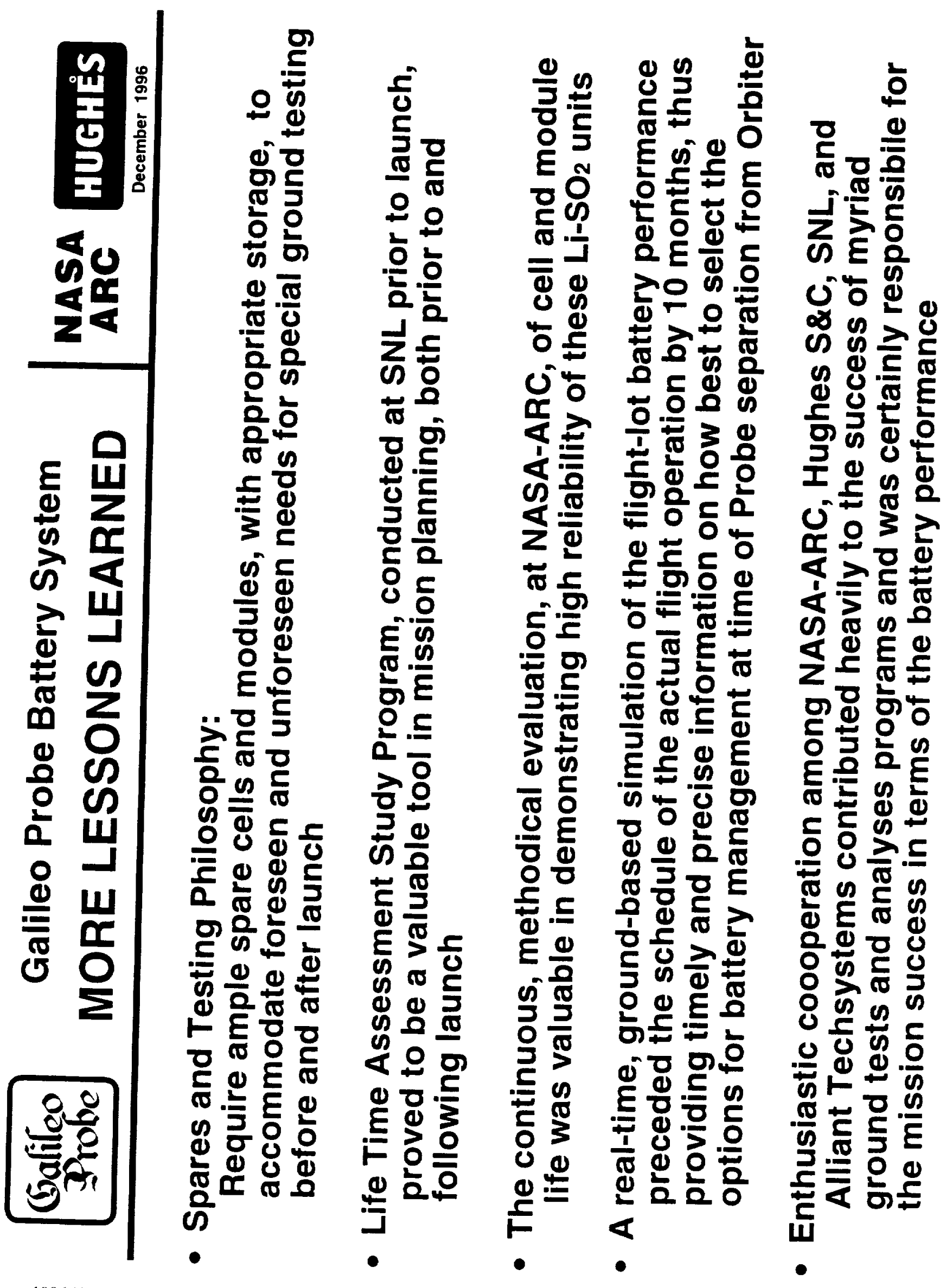

1996 N.4SA Aerospace Battery Workshop 